\title{
Anatomy and approaches along the cerebellar-brainstem fissures
}

\author{
Ken Matsushima, MD,,2 Kaan Yagmurlu, MD, ${ }^{1}$ Michihiro Kohno, MD, $\mathrm{PhD},{ }^{2}$ and \\ Albert L. Rhoton, Jr., MD' \\ 1Department of Neurological Surgery, University of Florida, Gainesville, Florida; and 'Department of Neurosurgery, Tokyo \\ Medical University, Tokyo, Japan
}

\begin{abstract}
OBJECTIVE Fissure dissection is routinely used in the supratentorial region to access deeply situated pathology while minimizing division of neural tissue. Use of fissure dissection is also practical in the posterior fossa. In this study, the microsurgical anatomy of the 3 cerebellar-brainstem fissures (cerebellomesencephalic, cerebellopontine, and cerebellomedullary) and the various procedures exposing these fissures in brainstem surgery were examined.

METHODS Seven cadaveric heads were examined with a microsurgical technique and 3 with fiber dissection to clarify the anatomy of the cerebellar-brainstem and adjacent cerebellar fissures, in which the major vessels and neural structures are located. Several approaches directed along the cerebellar surfaces and fissures, including the supracerebellar infratentorial, occipital transtentorial, retrosigmoid, and midline suboccipital approaches, were examined. The 3 heads examined using fiber dissection defined the anatomy of the cerebellar peduncles coursing in the depths of these fissures.
\end{abstract}

RESULTS Dissections directed along the cerebellar-brainstem and cerebellar fissures provided access to the posterior and posterolateral midbrain and upper pons, lateral pons, floor and lateral wall of the fourth ventricle, and dorsal and lateral medulla.

CONCLUSIONS Opening the cerebellar-brainstem and adjacent cerebellar fissures provided access to the brainstem surface hidden by the cerebellum, while minimizing division of neural tissue. Most of the major cerebellar arteries, veins, and vital neural structures are located in or near these fissures and can be accessed through them.

http://thejns.org/doi/abs/10.3171/2015.2.JNS142707

KEY WORDS brainstem; cerebellum; cerebellomedullary fissure; cerebellomesencephalic fissure; cerebellopontine fissure; microsurgical anatomy

$\mathrm{R}$ ECENT advances in microsurgical and endoscopic techniques, imaging, and electrophysiological monitoring have facilitated safe resection of brainstem lesions that were previously considered inoperable. . $^{3-5,9,11,12 \text {, }}$ 14-16,19,21, 23-26,37,38,40,44,62,64,65,70,73,75,79,86 The brainstem surface, when near to or accessed by the lesion, is the shortest and most direct path for surgical treatment. . $5,5,14,21,64,75,79$ Several safe entry zones have been proposed and used for lesions inside the brainstem. . $^{3,5,12,13,23,24,40,65,86}$ To maximize the chances of safe and precise removal of these lesions, sufficient exposure of the brainstem surface is critical, as is selection of an appropriate entry corridor into the brainstem.

Cerebral fissures, such as the sylvian fissure, are routinely opened in the supratentorial region to access deeply situated pathology without dividing any neural tissue. Fis- sure dissection has also been used in the infratentorial region. ${ }^{22,49,53,60,61}$ Opening the arachnoid membranes and trabeculae along the cerebellar-brainstem fissures, as in the telovelar or transcerebellomedullary fissure approaches, was originally proposed to access the pineal region, cranial nerve $(\mathrm{CN}) \mathrm{V}$, and the fourth ventricle..$^{22,49,60}$ However, brainstem surgery frequently requires the opening of the 3 cerebellar-brainstem fissures and/or adjacent cerebellar fissures to expose the cerebellar peduncles and brainstem surface hidden by the parts of the cerebellum forming the walls of the 3 cerebellar-brainstem fissures ${ }^{61,71}$ Most of the major cerebellar arteries, veins, and vital neural structures, including a majority of the CNs and all 3 cerebellar peduncles, are located inside or close to these fissures. $^{27,43,45,56,66,68,85}$ Detailed knowledge of these fissures is

ABBREVIATIONS AICA = anterior inferior cerebellar artery; $C N=$ cranial nerve; $\mathrm{PCA}=$ posterior cerebral artery; $\mathrm{PICA}=$ posterior inferior cerebellar artery; $\mathrm{SCA}=$ superior cerebellar artery.

SUBMITTED November 26, 2014. ACCEPTED February 3, 2015.

INCLUDE WHEN CITING Published online August 14, 2015; DOI: 10.3171/2015.2.JNS142707. 
required to be able to open them safely. This study examined the microsurgical anatomy of the cerebellar-brainstem and adjacent fissures and the various approaches through these fissures.

\section{Methods}

The cerebellar-brainstem and cerebellar fissures were examined in step-by-step microsurgical dissections of 7 cadaveric heads, and 3 brainstems with attached cerebella with the fiber dissection technique, both groups using the magnification (6-40) provided by the Zeiss Surgical Microscope (Carl Zeiss AG). No intracranial pathology was observed in any specimen. After formalin fixation, the arteries were perfused with red-colored and the veins with blue-colored silicone (Dow Corning Corp.), Thinner 200 (Dow Corning Corp.), and RTV catalyst (Dow Corning Corp.) as described previously. ${ }^{74}$ Bone dissections were performed with a Midas Rex drill (Midas Rex Institute). The method of cerebellar and brainstem fiber tract dissection is described elsewhere. ${ }^{86}$

\section{Results}

\section{Cerebellar-Brainstem and Cerebellar Fissures}

The cerebellum wraps around the posterior surface of the brainstem to create 3 cerebellar-brainstem fissures: cerebellomesencephalic, cerebellopontine, and cerebellomedullary (Fig. 1). 57,67 The cerebellomesencephalic fissure extends inferiorly between the cerebellum and midbrain, the cerebellopontine fissure is formed by the folding of the cerebellum around the lateral sides of the pons, and the cerebellomedullary fissure extends superiorly between the cerebellum and medulla. Each cerebellar-brainstem fissure is related to a part of the fourth ventricle. The cerebellomesencephalic fissure is related to the superior half of the roof, the cerebellopontine fissure to the lateral recesses, and the cerebellomedullary fissure to the inferior half of the roof of the fourth ventricle (Fig. 1E and F). The cerebellar surface is divided into a tentorial surface, which faces the tentorium; a petrosal surface, which faces forward toward the posterior surface of the temporal bone; and a suboccipital surface located below and between the transverse and sigmoid sinuses, which faces the inferior half of the occipital bone and is exposed in a suboccipital craniotomy (Fig. 1A-C).

The tentorial cerebellar surface is divided into 3 parts by the tentorial (primary) and postclival fissures and is separated from the posterior half of the midbrain by the cerebellomesencephalic fissure (Fig. 1A). The inferior part of the cerebellomesencephalic fissure ventral to the central lobule is often referred to as the precentral cerebellar fissure. The tentorial fissure is located between the quadrangular and simple lobules on the hemisphere and the culmen and declive on the vermis. The postclival fissure separates the simple and the superior semilunar lobules.

The major fissure on the petrosal cerebellar surface, the petrosal (horizontal) fissure, divides the surface into superior and inferior parts and extends onto the suboccipital cerebellar surface between the superior and inferior semi- lunar lobules (Fig. 1B). The petrosal surface wraps around the pons and the middle cerebellar peduncles to form the superior and inferior limbs of the cerebellopontine fissure. The cerebellopontine fissure is a V-shaped fissure. The petrosal and postclival fissures extend laterally and superiorly from the apex of the cerebellopontine fissure. The cerebellopontine fissure is continuous with the cerebellomesencephalic fissure superiorly and cerebellomedullary fissure inferiorly. Both the cerebellopontine and petrosal fissures are together called the horizontal or great horizontal fissure in the classic nomenclature..$^{57,67}$

The suboccipital fissure divides the suboccipital cerebellar surface into superior and inferior parts, the inferior semilunar and biventral lobules on the hemisphere, and the pyramid and tuber on the vermis (Fig. 1C). The vermian part of this fissure is classically called the prepyramidal fissure, and the hemispheric part is called the prebiventral fissure. ${ }^{57,67}$ The petrosal (horizontal) fissure, the most prominent fissure on the petrosal surface, extends onto the suboccipital surface between the superior and inferior semilunar lobules. The tonsillobiventral (secondary) fissure separates the tonsil and the biventral lobule on the inferior part of the suboccipital surface. The cerebellomedullary fissure extends superiorly between the cerebellum and medulla, separating the suboccipital surface from the dorsal half of the medulla.

\section{Cerebellomesencephalic Fissure}

The cerebellomesencephalic fissure extends downward between the midbrain and the cerebellum and is V-shaped when viewed superiorly (Fig. 2). The ventral wall of the fissure, which forms the outer surface of the superior part of the roof of the fourth ventricle, is composed of the lingula of the vermis, dorsal surface of the superior cerebellar peduncles, and the rostral surface of the middle cerebellar peduncles. The dorsal wall of the fissure is formed by the anterior surface of the culmen and central lobule in the midline and the quadrangular lobule and wing of the central lobule laterally. The lingula, a thin, narrow tongue of the vermis, sits on the outer surface of the superior (anterior) medullary velum (Fig. 2B). The superior cerebellar peduncles, which connect the dentate nucleus to the red nucleus and thalamus, form smooth longitudinal prominences on each side of the lingula. The interpeduncular sulcus, a continuation of the lateral mesencephalic sulcus, extends along the adjoining surfaces of the superior and middle cerebellar peduncles (Fig. 2B and F). The inferior cerebellar peduncle turns dorsally to cross lateral to the caudal part of the superior cerebellar peduncle at the caudal edge of the cerebellomesencephalic fissure (Fig. 2F). CN IV arises in the cerebellomesencephalic fissure below the inferior colliculus and passes anterolaterally to exit the anterior part of the fissure. This fissure opens superiorly into the quadrigeminal cistern in the midline, the site of the pineal gland and superior and inferior colliculi, and laterally into the ambient cistern, through which CN IV, the posterior cerebral artery (PCA), and basal vein pass.

The largest vessels coursing in the cerebellomesencephalic fissure are the superior cerebellar artery (SCA) and tributaries of the vein of Galen, including the veins of the cerebellomesencephalic fissure and superior cerebellar 

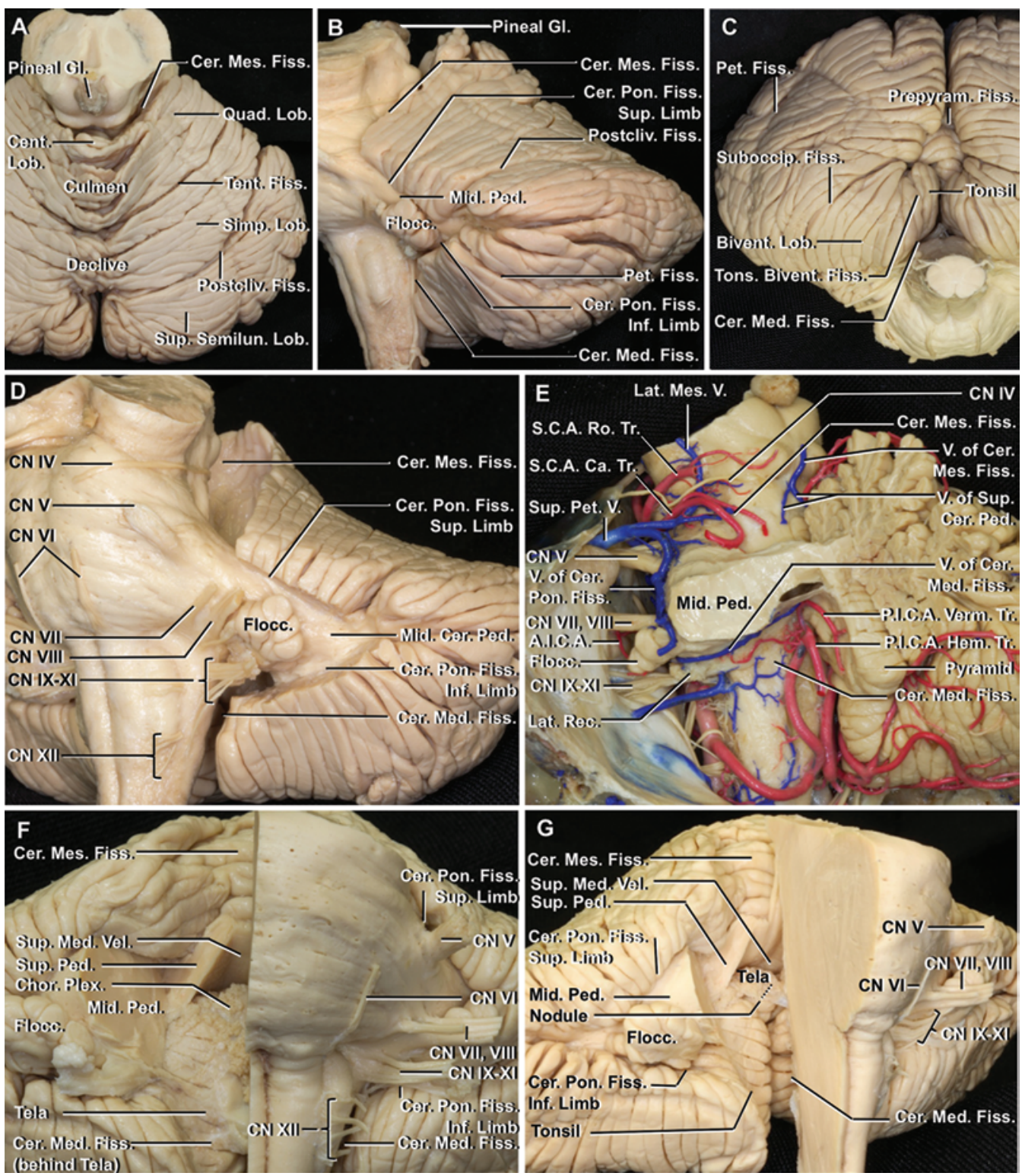

FIG. 1. Cerebellar-brainstem and cerebellar fissures and fourth ventricle. A: The tentorial (primary) and postclival fissures are located on the tentorial surface that faces the lower surface of the tentorium. The cerebellomesencephalic fissure, also referred to as the precentral cerebellar fissure, separates the tentorial surface from the dorsal surface of the midbrain. B: The petrosal surface faces forward toward the posterior surface of the temporal bone and wraps around the pons and the middle cerebellar peduncles to form the superior and inferior limbs of the cerebellopontine fissure. The petrosal (horizontal) and postclival fissures extend laterally and superiorly from the apex of the cerebellopontine fissure. The cerebellopontine fissure is continuous with the cerebellomesencephalic fissure superiorly and cerebellomedullary fissure inferiorly. C: The suboccipital surface, exposed in the suboccipital operative approaches and located below and between the sigmoid and transverse sinuses, is the site of the suboccipital fissure, which has a vermian part called the prepyramidal fissure, and a hemispheric part referred to as the prebiventral and tonsillobiventral (secondary) fissures. The cerebellomedullary fissure separates this surface from the medulla. D: Removing the cerebellar margin of the 3 cerebellar-brainstem fissures exposes the interior of the fissures and the areas of communication between these fissures. E: Posterolateral view. Removing the left half of the cerebellum exposes the 3 cerebellar-brainstem fissures and major vessels in these fissures. F: The right half of the brainstem has been removed to provide an anterior view of the cerebellomesencephalic and cerebellomedullary fissures, and the roof of the fourth ventricle formed, from rostral to caudal, by the superior and inferior medullary vela, and the tela choroidea, in which the choroid plexus arises. G: Removing the tela choroidea in the roof of the fourth ventricle exposes the surface of the nodule and tonsil facing the cerebellomedullary fissure. A.I.C.A. = anterior inferior cerebellar artery; Bivent. $=$ biventral; $\mathrm{Ca} .=$ caudal; Cent. $=$ central; Cer. $=$ cerebellar, cerebello; Chor. Plex. $=$ choroid plexus; $\mathrm{CN}=$ cranial nerve; Fiss. = fissure; Flocc. $=$ flocculus; Gl. = gland; Hem. = hemispheric; Inf. = inferior; Lat. = lateral; Lob. = lobule; Med. = medullary; Mes. $=$ mesencephalic; Mid. = middle; P.I.C.A. = posterior inferior cerebellar artery; Ped. = peduncle; Pet. = petrosal; Pon. = pontine; Postcliv. = postclival; Prepyram. = prepyramidal; Quad. = quadrangular; Rec. = recess; Ro. = rostral; S.C.A. = superior cerebellar artery; Semilun. = semilunar; Simp. = simple; Suboccip. = suboccipital; Sup. = superior; Tent. = tentorial; Tons. = tonsillo; Tr. = trunk; V. = vein; Vel. = velum; Verm. = vermian. 

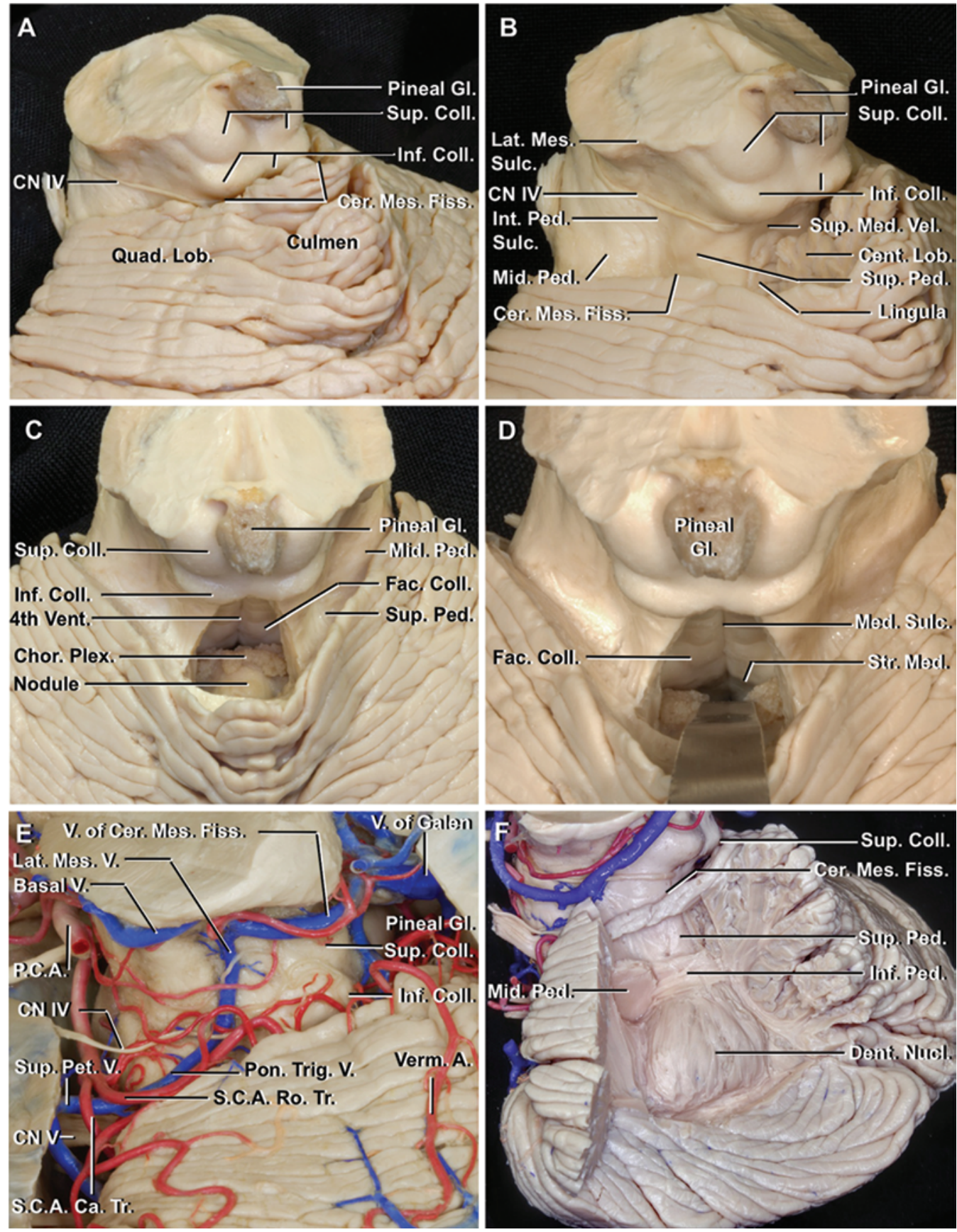

FIG. 2. Cerebellomesencephalic fissure. A: The cerebellomesencephalic fissure extends caudally between the midbrain and the cerebellum, and opens superiorly into the quadrigeminal cistern, the site of the pineal gland, superior and inferior colliculi, and origin of CN IV, and laterally into the ambient cistern along which CN IV courses. B: The left central lobule and anterior part of the quadrangular lobule have been removed to expose the superior medullary velum and lingula in the anterior wall of the cerebellomesencephalic fissure. C: The superior medullary velum was removed to expose the upper half of the fourth ventricle. The nodule, choroid plexus, and facial colliculi are exposed inside the fourth ventricle. D: The median sulcus, facial colliculus, and stria medullaris, crossing the floor of the fourth ventricle at the level of the lateral recess, are exposed after the nodule was retracted. The median sulcus above the facial colliculi, and the supra- and infrafacial triangles above and below the facial colliculi, have been proposed as brainstem safe entry zones. E: The main vessels coursing in the cerebellomesencephalic fissure are the SCA, veins of the cerebellomesencephalic fissure, and the lateral mesencephalic vein. The rostral and caudal trunks of the SCA enter the cerebellomesencephalic fissure after passing above CN V. The superior colliculi are supplied predominantly by the PCA, and the inferior colliculi by the SCA or its circumflex perforating branches. The vein of the cerebellomesencephalic fissure crosses the quadrigeminal cistern anterior to the central lobule and empties directly or through the superior vermian vein into the vein of Galen. The lateral mesencephalic vein courses along the lateral mesencephalic sulcus and communicates with the basal vein above and the superior petrosal vein below. F: The rostral part of the left half of the cerebellum has been removed to expose the superior cerebellar peduncle, which forms the medial part of the ventral wall of the cerebellomesencephalic fissure. The middle cerebellar peduncle forms part of the caudal wall of the cerebellomesencephalic fissure. The inferior cerebellar peduncle passes lateral to the junction of the superior cerebellar peduncle and dentate nucleus at the caudal edge of the cerebellomesencephalic fissure. FIG. 2. (continued) $\rightarrow$ 
FIG. 2. A. = artery; Ca. = caudal; Cent. = central; Cer. = cerebello; Chor. Plex. = choroid plexus; $C N=$ cranial nerve; Coll. = colliculus; Dent. = dentate; Fac. = facial; Fiss. = fissure; Gl. = gland; Inf. = inferior; Int. Ped. = interpeduncular; Ped. = peduncle; Lat. = lateral; Lob. = lobule; Med. = median, medullary; Mes. = mesencephalic; Mid. = middle; Nucl. = nucleus; P.C.A. = posterior cerebral artery; Ped. = peduncle; Pet. = petrosal; Pon. Trig. = pontotrigeminal; Quad. = quadrangular; Ro. = rostral; S.C.A. = superior cerebellar artery; Str. Med. = stria medullaris; Sulc. = sulcus; Sup. = superior; Tr. = trunk; V. = vein; Vel. = velum; Vent. = ventricle; Verm. = vermian .

peduncle, and the lateral mesencephalic vein (Figs. 1E and 2E). The SCA enters the cerebellomesencephalic fissure, after encircling the brainstem near the pontomesencephalic junction, passing below $\mathrm{CN}$ IV and above CN V. It usually bifurcates into rostral and caudal trunks near $\mathrm{CN}$ $\mathrm{V}$ before entering the cerebellomesencephalic fissure. A meningeal branch occasionally originates from the main or rostral trunk near where the artery passes under the tentorium, and enters the free edge of the tentorium. The cerebellomesencephalic segment of the SCA makes several sharp turns in the fissure and is frequently intertwined with CN IV, and gives rise to the precerebellar arteries, which supply the deep cerebellar white matter and the dentate nucleus, and to hemispheric and vermian branches, supplying the tentorial cerebellar surface. The SCA supplies the superior and middle cerebellar peduncles and inferior colliculi in the cerebellomesencephalic fissure, often by the circumflex perforating arteries, which wind around the brainstem. The superior colliculi are supplied predominantly by the PCA.

The paired veins of the superior cerebellar peduncle originate deep in the cerebellomesencephalic fissure, course upward on the superior cerebellar peduncles just lateral to the lingula, and join near the rostral tip of the lingula to form the vein of the cerebellomesencephalic fissure, also called the precentral cerebellar vein, which crosses the quadrigeminal cistern anterior to the central lobule to drain either directly or through the superior vermian vein into the vein of Galen, as a bridging vein (Fig. 1E). The lateral mesencephalic vein courses in the lateral mesencephalic sulcus and usually empties into the basal vein. The inferior end of the lateral mesencephalic vein often anastomoses through the pontotrigeminal vein with a superior petrosal vein. $27,56,66,68$

\section{Approaches to or Through the Cerebellomesencephalic Fissure}

Approaches that involve the opening of the cerebellomesencephalic fissure include the variations of the supracerebellar infratentorial, occipital transtentorial, and superior transvelar approaches (Fig. 3). Sacrificing some bridging veins draining into the torcula may be required to reach the quadrigeminal region through the midline supracerebellar infratentorial approach. Opening the thick arachnoid membrane of the quadrigeminal cistern and the superficial part of the cerebellomesencephalic fissure exposes the Galenic venous complex including the vein of the cerebellomesencephalic fissure, $\mathrm{P}_{3}$ segment of the PCAs extending medial to the tentorial edge, pineal gland, posterior wall of the midbrain including the upper part of the collicular plate, and third ventricle, which can be exposed between the splenium and pineal body (Fig. 3A). It is difficult to see and open the full depth of the cerebellomesencephalic fissure hidden anterior to the vermis, but superficial arachnoid dissection along the cerebellomesencephalic fissure facilitates retraction of the vermis and mobilization of the vein of the cerebellomesencephalic fissure and superior vermian vein.

The paramedian variant of the supracerebellar infratentorial approach provides access to the pineal region and ipsilateral part of the cerebellomesencephalic fissure while avoiding the obstruction in the midline by the culmen (Fig. 3B). The paramedian approach, directed off-midline above the quadrangular lobule lateral to the vermis, accesses the quadrigeminal and ambient cisterns, pineal gland, and superior colliculi without sacrificing bridging veins in the midline. Opening the superior part of the cerebellomesencephalic fissure provides more inferior exposure of the posterior midbrain, including the inferior colliculus and CN IV. Caution is needed to avoid damage to CN IV and the tortuous branches of the SCA coursing in the cerebellomesencephalic fissure, including the meningeal branch to the tentorial edge.

The extreme lateral variant of the supracerebellar infratentorial approach directed adjacent to the asterion and upper sigmoid sinus accesses the posterolateral aspect of the midbrain adjacent to the lateral mesencephalic sulcus, superior cerebellar peduncle, and CN IV (Fig. 3C). Opening the superior part of the cerebellomesencephalic fissure makes retraction of the cerebellum easier and enables a more inferior exposure, including the posterolateral surface of the upper pons and CN V. Opening the superior edge of the cerebellopontine fissure and the arachnoid membrane around the tributaries of the superior petrosal veins, including the pontotrigeminal and anterolateral marginal veins, aids in reducing tension on the superior petrosal veins, tortuous branches of the SCA, meningeal branch to the tentorial edge, and the pontotrigeminal vein connecting the lateral mesencephalic vein with the superior petrosal veins.

In the occipital transtentorial approach, the occipital lobe is retracted and the tentorium is divided along the edge of the straight sinus to provide a slightly off-midline approach to the fissure (Fig. 3D). This approach provides a more superior view of the ipsilateral half of the cerebellomesencephalic fissure, and better visualization into the depth of the fissure, as compared with the supracerebellar infratentorial approach. It provides access to the splenium above the vein of Galen, pineal gland, and superior colliculi (Fig. 3E). Opening the superior part of the cerebellomesencephalic fissure and gentle retraction of the cerebellum exposes the inferior colliculi and CN IV (Fig. 3F). Extending the dissection into the inferior part of the cerebellomesencephalic fissure exposes the thin, white, superior medullary velum in the midline (Fig. 3G). The superior medullary velum, with the lingula on its outer surface, is a relatively avascular structure that roofs the superior half of the fourth ventricle. A midline linear incision through this velum provides access to the upper half 

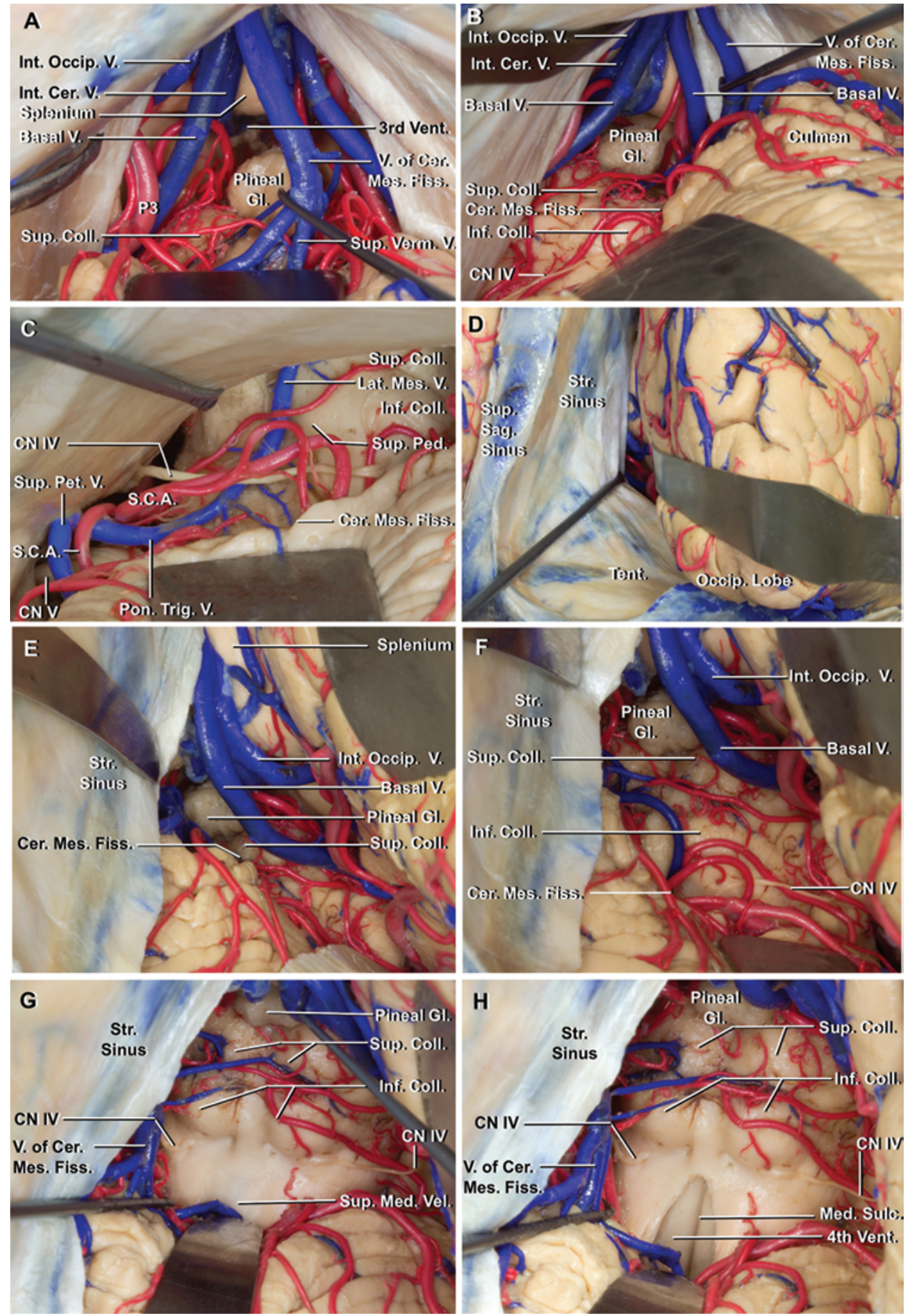

FIG. 3. Surgical approaches to the cerebellomesencephalic fissure. A-C: Median, paramedian, and extreme lateral supracerebellar infratentorial approaches. A: The Galenic venous complex including the vein of the cerebellomesencephalic fissure, $\mathrm{P}_{3}$ segment of the PCAs, pineal gland, posterior surface of the midbrain including the superior colliculi, and the third ventricle have been exposed through the midline supracerebellar infratentorial approach. Opening the superficial part of the cerebellomesencephalic fissure, and gentle retraction of the vermis and the vein of the cerebellomesencephalic fissure and superior vermian vein facilitates exposure of the quadrigeminal region. B: The left paramedian variant of the supracerebellar infratentorial approach provides greater access to the ipsilateral half of the cerebellomesencephalic fissure and avoids the obstruction by the culmen in the midline approach. Opening the superior part of the cerebellomesencephalic fissure exposes the inferior colliculus and CN IV. C: The extreme lateral variant of the supracerebellar infratentorial approach directed adjacent to the asterion and sigmoid sinus provides access to the posterolateral midbrain adjacent to the lateral mesencephalic sulcus and vein, superior cerebellar peduncle, and CN IV. Opening the superior part of the cerebellomesencephalic fissure with gentle cerebellum retraction extends the exposure downward to include the posterior wall of the upper pons and CN V. D-F: Right occipital transtentorial approach. D: The occipital lobe is retracted away from the falx and straight sinus. E: The tentorium has been divided adjacent to the straight sinus, and the splenium, pineal gland, and superior colliculus have been exposed. F: Opening the superior part of the cerebellomesencephalic fissure and gently retracting the cerebellum exposes the inferior colliculus and CN VI. FIG. 3. (continued) $\rightarrow$ 
FIG. 3. This approach provides a more superior and deeper view into the ipsilateral cerebellomesencephalic fissure than the supracerebellar infratentorial approach. G and H: Superior transvelar approach. G: The superior medullary velum, a thin, white, and relatively avascular membrane in the upper half of the roof of the fourth ventricle, has been exposed below the inferior colliculi. $\mathrm{H}$ : Opening the superior medullary velum exposes the upper part of the fourth ventricle and the median sulcus. Cer. = cerebello, cerebral; $\mathrm{CN}=$ cranial nerve; Coll. = colliculus; Fiss. = fissure; $\mathrm{Gl}$. = gland; Inf. = inferior; Int. = internal; Lat. = lateral; Med. = median, medullary; Mes. = mesencephalic; Occip. = occipital; Ped. = peduncle; Pet. = petrosal; Pon. Trig. = pontotrigeminal; S.C.A. = superior cerebellar artery; Sag. = sagittal; Str. = straight; Sulc. = sulcus; Sup. = superior; Tent. = tentorium; V. = vein; Vel. = velum; Vent. = ventricle; Verm. = vermian .

of the fourth ventricle and its floor. The dorsal wall of the upper fourth ventricle was opened in this study to yield a wider view (Fig. 3H).

\section{Cerebellopontine and Petrosal Fissures}

The cerebellopontine fissure is a V-shaped fissure formed by the petrosal surface of the cerebellum wrapping around the pons and the middle cerebellar peduncle (Figs. $1 \mathrm{D}$ and $4 \mathrm{~A}$ and $\mathrm{E})$. The superior and inferior limbs of the fissure meet at a lateral apex, located lateral to the flocculus. The petrosal fissure extends laterally from the apex of the cerebellopontine fissure to split the petrosal cerebellar surface into superior and inferior parts, and wraps onto the suboccipital cerebellar surface between the superior and inferior semilunar lobules (Fig. 1B). The postclival fissure on the tentorial cerebellar surface also merges into the apex of the cerebellopontine fissure to form the suprafloccular cistern. ${ }^{47} \mathrm{CNs}$ V, VII, and VIII arise between the superior and inferior limbs of the cerebellopontine fissure. The flocculus and rhomboid lip extend laterally with the choroid plexus from the foramen of Luschka ventral to the lower limb of the fissure (Fig. 4B). The rhomboid lip is a sheet-like layer of neural tissue attached to the lateral margin of the ventricular floor that extends posterior to CNs IX and $\mathrm{X}$ and joins the tela choroidea to form a pouch at the outer extremity of the lateral recess. The dorsal cochlear nucleus produces a smooth prominence on the dorsal surface of the inferior cerebellar peduncle in the floor of the lateral recess. The inferior cerebellar peduncle courses upward along the dorsolateral medulla and turns dorsally to form the medial part of the rostral wall of the lateral recess (Fig. 4E and F). The junction of CNs IX and X with the medulla is positioned ventral to the junction of the cerebellopontine and cerebellomedullary fissures.

The anterior inferior cerebellar artery (AICA) and the vein of the cerebellopontine fissure are the main vessels running in and along the cerebellopontine fissure (Fig. 4C). The caudal trunk of the SCA and its hemispheric branches may also run in or near the superior limb or apex of the cerebellopontine fissure, and along the anterolateral margin of the cerebellum. The AICA arises from the basilar artery, and commonly bifurcates near CNs VII and VIII to form rostral and caudal trunks. The rostral trunk sends its branches laterally along the middle cerebellar peduncle and superior limb of the cerebellopontine fissure, and the adjoining part of the petrosal cerebellar surface. The caudal trunk supplies the inferior part of the petrosal cerebellar surface, including a part of the flocculus and the choroid plexus. This artery has marked variability, but one or both of these trunks or their branches often course in or near the limbs of the cerebellopontine or petrosal fissure when passing around the flocculus to supply the petrosal cerebellar surface.
The vein of the cerebellopontine fissure, formed by the union of several tributaries including the veins of the petrosal fissure, middle cerebellar peduncle, and cerebellomedullary fissure, is the most frequent and largest vein draining the petrosal cerebellar surface. It originates near the apex of the cerebellopontine fissure, courses in or near the superior limb of the fissure, and empties through the superior petrosal veins into the superior petrosal sinus. The vein of the middle cerebellar peduncle is formed by the union of the vein of the pontomedullary sulcus with the lateral medullary vein or the vein of the inferior cerebellar peduncle, and ascends on the lateral surface of the middle cerebellar peduncle near the base of the cerebellopontine fissure, medial to the flocculus, and usually empties into a superior petrosal vein posterior to the junction of $\mathrm{CN} \mathrm{V}$ with the brainstem. The vein of the cerebellomedullary fissure, if it passes dorsal to the flocculus, courses in or along the inferior limb of this fissure before draining into the vein of the cerebellopontine fissure (Fig. 4D).

\section{Approaches Along the Cerebellopontine Fissure}

\section{Supra- and Infrafloccular Approaches}

Opening the dura in a retrosigmoid craniotomy exposes the suboccipital surface. Following the petrosal fissure from the suboccipital surface to the petrosal surface leads to the apex of the cerebellopontine fissure (Fig. 5A). In the suprafloccular approach, gentle retraction of the cerebellum exposes the apex of the cerebellopontine fissure just dorsolateral to the flocculus. Opening the suprafloccular cistern releases CSF, relaxes the cerebellum, and aids in identification of the vein of the cerebellopontine fissure. Opening the arachnoid along the superior limb of the cerebellopontine fissure rostral to the flocculus exposes the vein of the cerebellopontine fissure, usually the largest of the veins emptying into the superior petrosal sinus, the root entry zone of CN V, and middle cerebellar peduncle (Fig. 5B). Care is taken to avoid placing too much tension on the superior petrosal veins. Rostral retraction of the superior semilunar lobule provides wider access to the peritrigeminal area. Inferior retraction of the flocculus provides a superior view of the lateral part of the pontomedullary sulcus. Branches of the SCA and AICA, and the vein of the cerebellopontine fissure coursing along the fissure should be preserved during this exposure. Attention is directed to also identifying the vein of the middle cerebellar peduncle ascending on the lateral pons just anterior to the flocculus, and the pontotrigeminal vein running at the upper end of this fissure.

In the infrafloccular approach, directed through a lower retrosigmoid craniotomy, the flocculus is elevated after the lower part of the inferior limb of the cerebellopontine fissure and superolateral edge of the cerebellomedullary fissure are opened, exposing the junction of CNs VII and 

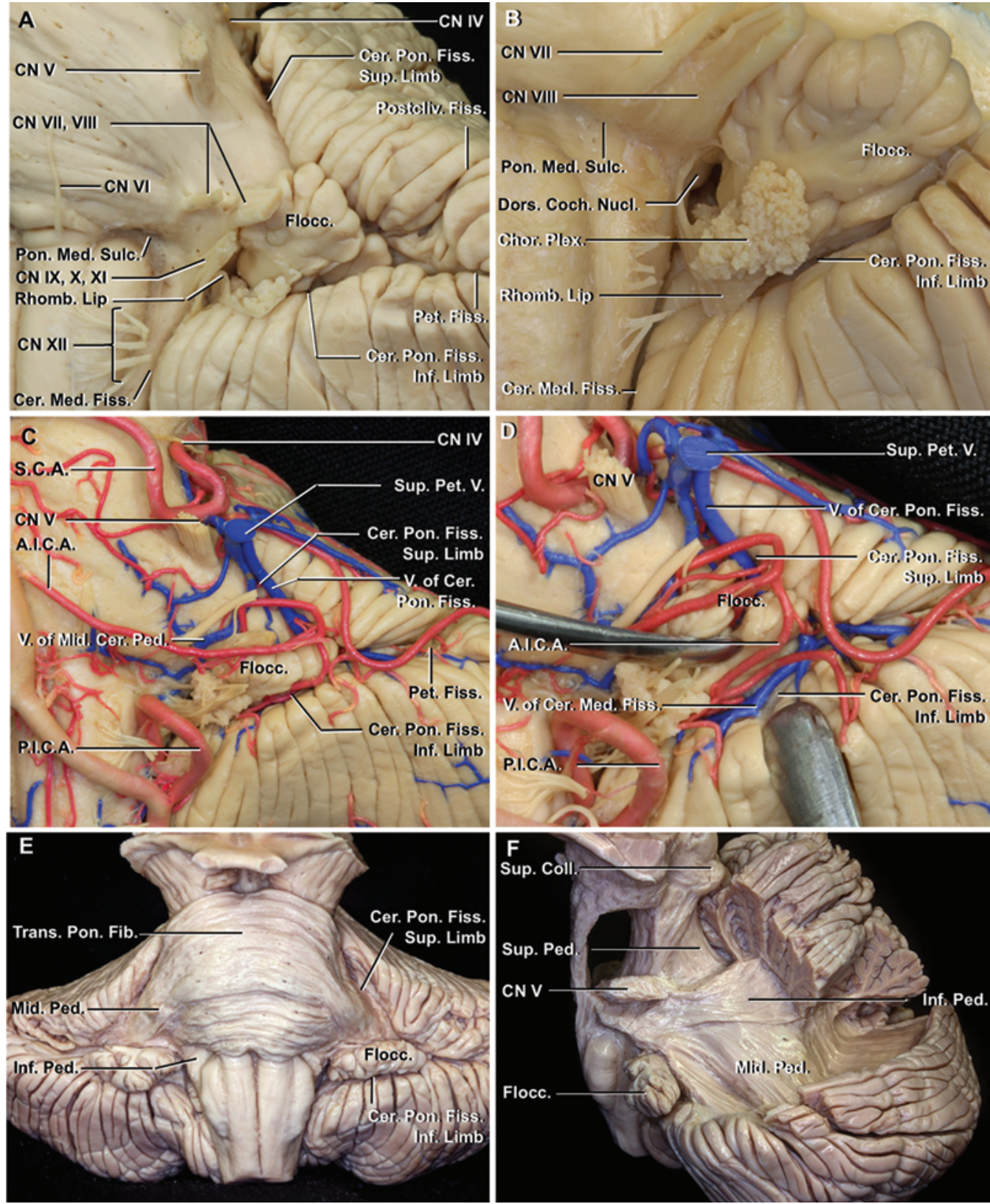

FIG. 4. Cerebellopontine fissure. A: The cerebellopontine fissure is a V-shaped fissure formed by the cerebellum wrapping around the pons and the middle cerebellar peduncles. The petrosal fissure extends laterally from its apex onto the suboccipital surface, and the postclival fissure extends superiorly from the apex onto the tentorial surface. B: Enlarged view. The flocculus, rhomboid lip, and choroid plexus extend laterally from the foramen of Luschka above the inferior limb and anterior to the apex of the fissure. The dorsal cochlear nucleus is exposed and can be seen through the foramen of Luschka in the lateral recess. C: The AICA and the vein of the cerebellopontine fissure are the main vessels coursing along the cerebellopontine fissure. The caudal trunk of the SCA and its lateral hemispheric branches may run in or near the superior limb or apex of the cerebellopontine fissure, and along the anterolateral margin of the cerebellum. The vein of the middle cerebellar peduncle ascends medial to the flocculus on the lateral surface of the middle cerebellar peduncle near the base of the cerebellopontine fissure. D: The vein of the cerebellomedullary fissure courses along the inferior limb of the cerebellopontine fissure and drains into the vein of the cerebellopontine fissure. E: The middle cerebellar peduncle formed by the transverse pontine fibers passes dorsally between the superior and inferior limbs of the cerebellopontine fissure, to enter the cerebellum. The inferior cerebellar peduncle ascends along the dorsolateral medulla just below the pontomedullary junction and the junction of the cerebellopontine and cerebellomedullary fissures. F: Lateral view. Some middle cerebellar peduncle fibers have been removed to expose the inferior cerebellar peduncle passing lateral to the middle and superior cerebellar peduncles to connect the spinal cord and vermis. A.I.C.A. = anterior inferior cerebellar artery; Cer. $=$ cerebellar, cerebello; Chor. Plex. $=$ choroid plexus; $C N=$ cranial nerve; Coch. $=$ cochlear; Coll. $=$ colliculus; Dors. $=$ dorsal; Fib. = fibers; Fiss. $=$ fissure; Flocc. $=$ flocculus; Inf. $=$ inferior; Med. = medullary; Mid. $=$ middle; Nucl. $=$ nucleus; P.I.C.A. $=$ posterior inferior cerebellar artery; Ped. = peduncle; Pet. = petrosal; Pon. = pontine, ponto; Postcliv. = postclival; Rhomb. = rhomboid; S.C.A. $=$ superior cerebellar artery; Sulc. = sulcus; Sup. = superior; Trans. = transverse; $\mathrm{V}$. = vein. 

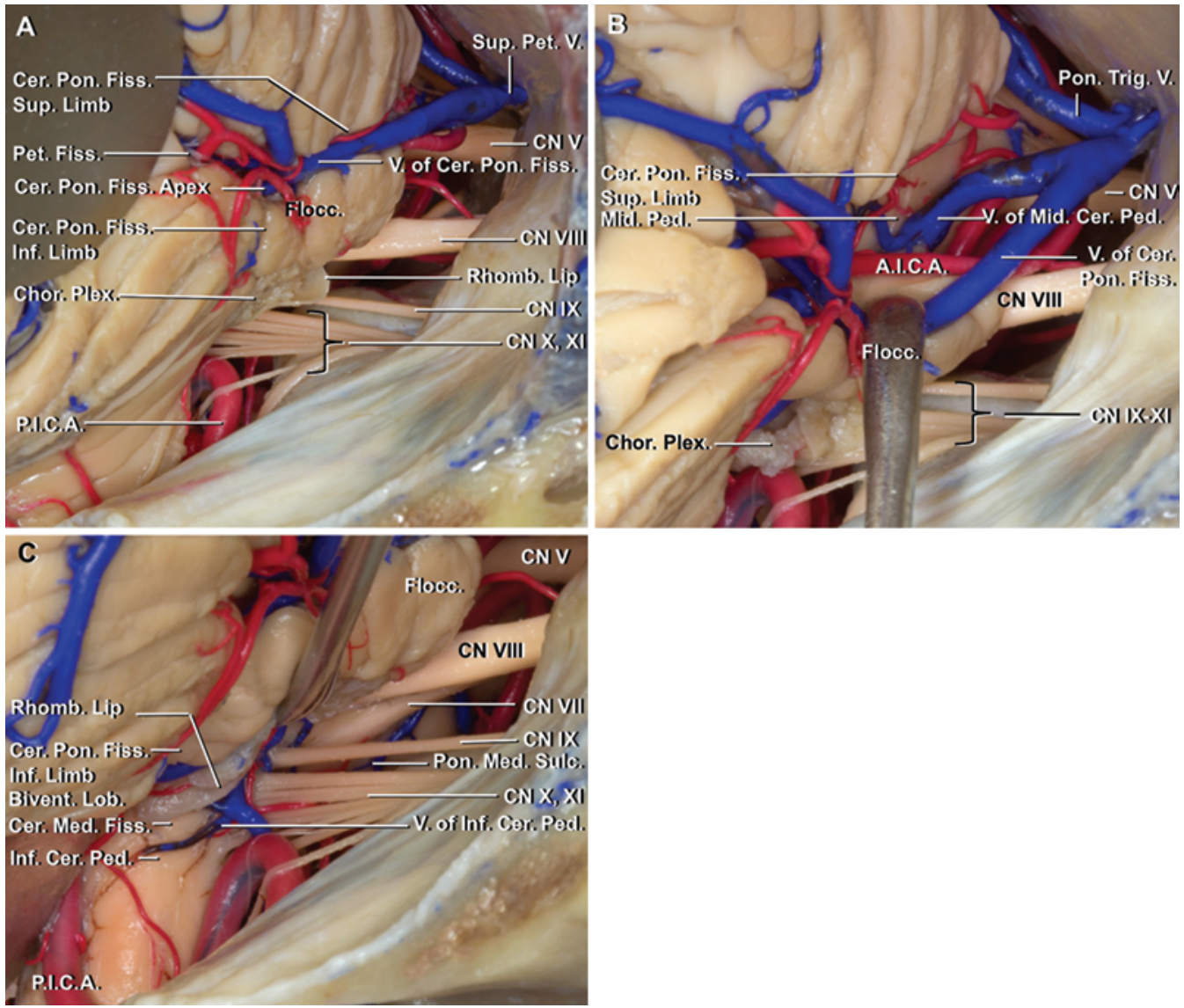

FIG. 5. Approaches to the cerebellopontine fissure. Retrosigmoid exposure of the right cerebellopontine fissure. A: View before the cerebellopontine fissure is opened. The vein of the cerebellopontine fissure runs along the superior limb of the fissure. The foramen of Luschka, rhomboid lip, and choroid plexus are located above the inferior limb. The suprafloccular cistern, located above the flocculus at the apex of the cerebellopontine fissure, is a site to open the arachnoid to drain CSF and identify the vein of the cerebellopontine fissure. B: Supraflocculuar approach. Opening the arachnoid along the superior limb of the cerebellopontine fissure in the suprafloccular approach provides access to the lateral surface of the middle cerebellar peduncle and trigeminal nerve. The vein of the cerebellopontine fissure has been gently retracted caudally. C: Infrafloccular approach. Opening the lower part of the inferior limb of the cerebellopontine fissure and superolateral edge of the cerebellomedullary fissure allows elevation of the flocculus, rhomboid lip, and choroid plexus, to expose the junction of CN VII and VIII with the brainstem, dorsolateral medulla, posterior surface of the inferior cerebellar peduncle, and the part of the pontomedullary sulcus deep to the nerves. A.I.C.A. = anterior inferior cerebellar artery; Bivent. = biventral; Cer. = cerebellar, cerebello; Chor. Plex. = choroid plexus; $\mathrm{CN}=$ cranial nerve; Fiss. $=$ fissure; Flocc. $=$ flocculus; Inf. = inferior; Lob. = lobule; Med. = medullary; Mid. = middle; P.I.C.A. = posterior inferior cerebellar artery; Ped. = peduncle; Pet. = petrosal; Pon. = pontine, ponto; Rhomb. = rhomboid; Sulc. = sulcus; Sup. = superior; Trig. = trigeminal; V. = vein

VIII with the brainstem (Fig. 5C). Removal of CSF from the cerebellomedullary cistern or lateral part of the cisterna magna, and elevation of the inferior part of the petrosal cerebellar surface exposes the lower CNs and jugular foramen. Small bridging veins extending from the brainstem near CNs IX and X to the jugular bulb, called vagal, glossopharyngeal, or inferior petrosal veins, are occasionally encountered in this region. Opening the lateral edge of the cerebellomedullary fissure exposes the rhomboid lip inferior to the flocculus, and allows elevation of the flocculus and choroid plexus at the foramen of Luschka. The posterior inferior cerebellar artery (PICA) entering into the cerebellomedullary fissure, branches of the AICA running below the lateral recess, and the veins of the inferior cerebellar peduncle and cerebellomedullary fissure are carefully preserved. The junction of CNs VII-X with the brainstem and the lateral surface of the inferior cerebellar peduncle are exposed by elevating the choroid plexus and flocculus at the lateral recess. Opening the lateral edge of the cerebellomedullary fissure facilitates the superomedial elevation of the biventral lobule to expose the dorsolateral medulla without extending the suboccipital craniotomy to the midline.

\section{Cerebellomedullary and Tonsillobiventral Fissures}

The cerebellomedullary fissure extends superiorly between the cerebellum and medulla. The ventral wall is formed by the posterior surface of the medulla, the inferior medullary velum, and the tela choroidea (Fig. 6). The dorsal wall is formed by the uvula and nodule of the vermis medially and the tonsils and biventral lobules laterally. The cerebellomedullary fissure is separated from the 

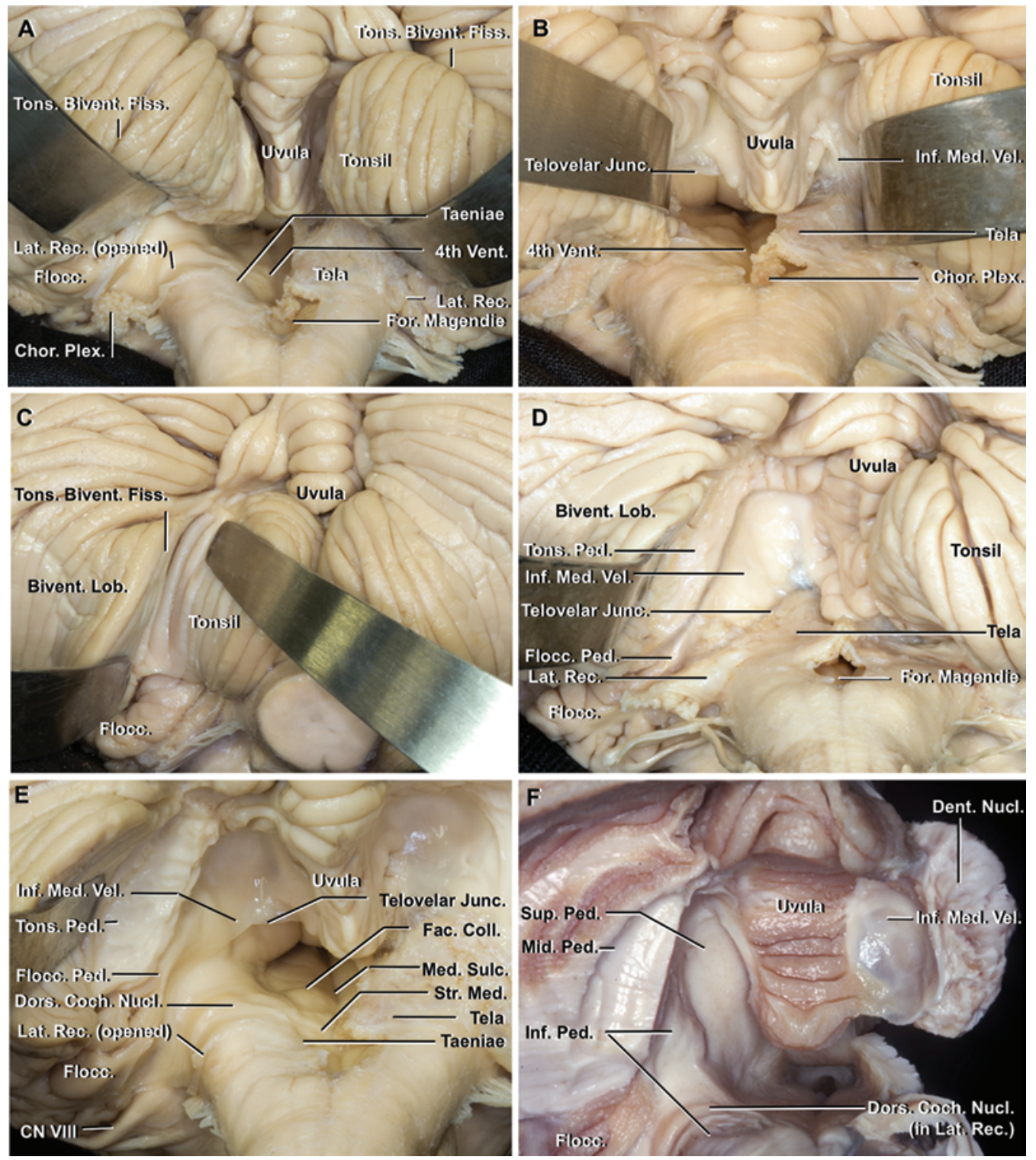

FIG. 6. Cerebellomedullary fissure. A: Elevation of the tonsil and biventral lobule and opening of the medullotonsillar space and lateral recess provides access to the fourth ventricle, lateral recess, and lower surface of the flocculus. The spatula is on the tonsillobiventral fissure. The floor of the fourth ventricle and the left lateral recess have been exposed by incising the tela adjacent to the inferolateral margin of the fourth ventricle and lateral recess. B: Opening the uvulotonsillar space by retracting the tonsil laterally exposes the supratonsillar space and provides access to the telovelar junction and inferior medullary velum. C: Opening the left tonsillobiventral fissure exposes the tonsillar peduncle at the superolateral edge of the tonsil, and provides access to the area just below the dentate nucleus and middle and inferior cerebellar peduncles. D: The left tonsillar peduncle has been divided and the tonsil removed. The tonsillar peduncle, located along the superolateral margin of the tonsil, is the only neural attachment of the tonsil to the remainder of the cerebellum. E: Both tonsils have been removed and the tela and left lateral recess have been opened. The peduncle of the flocculus, the connection between the lateral edge of the inferior medullary velum and the flocculus, is located just ventral to the tonsillar peduncle. The lateral recess, the site of the dorsal cochlear nucleus, is located ventral to the peduncle of the flocculus. The striae medullaris and facial colliculus, which are landmarks for the safe entry zones in the floor of the fourth ventricle, are exposed on the left half of the floor. F: The tonsillar peduncle is formed mainly by fibers of the middle cerebellar peduncle. The inferior cerebellar peduncle is located ventromedial to the middle cerebellar peduncle, and forms the inferior half of the lateral wall of the fourth ventricle. The dorsal cochlear nucleus sits on the dorsal surface of the inferior cerebellar peduncle. Bivent. = biventral; Chor. Plex. = choroid plexus.; $\mathrm{CN}=$ cranial nerve; Coch. $=$ cochlear; Coll. = colliculus; Dent. = dentate; Dors. $=$ dorsal; Fac. $=$ facial; Fiss. $=$ fissure; Flocc. $=$ flocculus, floccular; For. $=$ foramen; Inf. $=$ inferior; Junc. $=$ junction; Lat. $=$ lateral; Lob. = lobule; Med. = median, medullary; Mid. = middle; Nucl. = nucleus; Ped. = peduncle; Rec. = recess; Str. Med. = stria medullaris; Sulc. = sulcus; Sup. = superior; Tons. = tonsillar, tonsillo; Vel. = velum; Vent. = ventricle. 
fourth ventricle by the tela choroidea and inferior medullary vellum, and communicates with the ventricle through the foramen of Magendie. The cerebellomedullary fissure also communicates below the lateral recess and around the foramen of Luschka with the cerebellopontine fissure. CNs IX-XII are located in the cerebellomedullary cistern just ventrolateral to the lateral margin of the cerebellomedullary fissure. The cisternal spaces in the cerebellomedullary fissure have been divided as follows: 1) supratonsillar space between the tonsil dorsally, and the inferior medullary velum and superior part of the tela choroidea ventrally; 2) uvulotonsillar space between the uvula medially, and the tonsil laterally; and 3) medullotonsillar space between the tonsil and biventral lobule dorsally, and the medulla and tela choroidea ventrally (Fig. 6A and B). ${ }^{51,53}$ The tonsillobiventral fissure separates the tonsil and the biventral lobule (Fig. 6C). The tonsillar peduncle, a white matter bundle along the superolateral margin of the tonsil and formed mainly by fibers of the middle cerebellar peduncle fibers is the only attachment of the tonsil to the adjacent cerebellum (Fig. 6D-F). To summarize, the tonsil is surrounded by cisternal extensions of the cerebellomedullary fissure: the supratonsillar space rostrally, uvulotonsillar space medially, tonsillobiventral space laterally, and medullotonsillar space ventrally, and faces the cisterna magna dorsally and caudally. The inferior cerebellar peduncle forms the lateral wall of the inferior half of the fourth ventricle, and courses just ventral to the dorsal cochlear nucleus in the lateral recess (Fig. 6F). The superior cerebellar peduncle forms the lateral wall of the superior half of the fourth ventricle.

The major vessels in the cerebellomedullary fissure are the PICA and the veins of the cerebellomedullary fissure and inferior cerebellar peduncle. After crossing rostral to or between CNs IX-XI, the PICA usually passes near the lateral recess to enter the cerebellomedullary fissure and then caudally to reach the inferior pole of the tonsil where it makes a caudal loop, often near the inferior pole of the tonsil. It then ascends along the medial surface of the tonsil toward the roof of the fourth ventricle and turns dorsally to exit the fissure between the vermis, tonsil, and hemisphere to reach the suboccipital cerebellar surface. It often forms a loop with a convex rostral curve near the cranial pole of the tonsil, called the cranial loop, before exiting the fissure. The PICA gives off perforating arteries to the medulla before entering and while inside the cerebellomedullary fissure, and choroidal branches inside this fissure, which supply the tela choroidea and choroid plexus of the fourth ventricle. Most PICAs bifurcate into a vermian and a hemispheric trunk upon exiting the cerebellomedullary fissure. The trunks and branches of the PICA often course in or on the tonsillobiventral fissures during or after reaching the suboccipital cerebellar surface.

The vein of the cerebellomedullary fissure originates on the lateral edge of the nodule and uvula, courses laterally near or along the junction between the inferior medullary velum and tela choroidea, and dorsal or ventral to the flocculus, to reach the cerebellopontine angle (Fig. 1E). The vein of the inferior cerebellar peduncle courses on the peduncle parallel and several millimeters lateral to the inferolateral edge of the fourth ventricle, from the foramen of Magendie to the lateral recess. The veins of the cerebellomedullary fissure and inferior cerebellar peduncle drain into the cerebellopontine angle through the communication between the cerebellomedullary and cerebellopontine fissures and often empty into the vein of the middle cerebellar peduncle near the lateral end of the pontomedullary sulcus.

\section{Approaches Along the Cerebellomedullary and Tonsillobiventral Fissures}

Telovelar, Transcerebellomedullary Fissure, and Supratonsillar Approaches

Opening the cerebellomedullary fissure is referred to as the telovelar or transcerebellomedullary fissure approach (Fig. 7). ${ }^{49,51,60}$ After exposing the suboccipital cerebellar surface, the medullotonsillar and/or uvulotonsillar extension of the cerebellomedullary fissure are opened along the surfaces of the tonsil, uvula, and the biventral lobule. Opening the medullotonsillar space by gentle dorsal retraction of the tonsil and biventral lobule provides access to the fourth ventricle, lateral recess, and inferior surface of the flocculus (Figs. 6A and 7B). Placing the spatula along the tonsillobiventral fissure elevates both the tonsil and biventral lobule simultaneously. Incision of the tela adjacent to the taeniae, its attachment along the inferolateral margin of the fourth ventricle and caudal wall of the lateral recess, will expose the lateral recess and lateral wall of the fourth ventricle. Opening the uvulotonsillar space by retracting the tonsil laterally exposes the supratonsillar space and the caudal half of the roof of the fourth ventricle formed by the tela and inferior medullary velum (Figs. 6B and $7 \mathrm{C}$ ). The telovelar junction and vein of the cerebellomedullary fissure coursing laterally along or near the junction are good landmarks for determining how far the fissure has been opened. Extending the opening through the inferior medullary velum provides access to the entire rostrocaudal length of the fourth ventricle floor from the aqueduct to the obex, including the superior half of its lateral wall.

Opening the tonsillobiventral fissure exposes the tonsillar peduncle, the only neural site of attachment of the tonsil to the remainder of the cerebellum. It also provides access to the middle and inferior cerebellar peduncles and the dentate nucleus located in the cerebellum just above the supratonsillar space (Figs. 6C-F, and 7D and E). The middle cerebellar peduncle is located at the dorsal part of this access, and the inferior cerebellar peduncle is located at the ventral part. The main trunk of the PICA or its postbifurcation vermian and hemispheric trunks often run through the tonsillobiventral fissure to reach the suboccipital cerebellar surface, and sends branches into the walls of the fissure. Tributaries of the inferior vermian vein including the lateral tonsillar veins are often encountered on the tonsillobiventral fissure.

\section{Discussion}

\section{Cerebellomesencephalic Fissure}

On the dorsal wall of the midbrain and upper pons, the supra- and infracollicular areas, lateral mesencephalic sulcus, and the median sulcus above the facial colliculus 

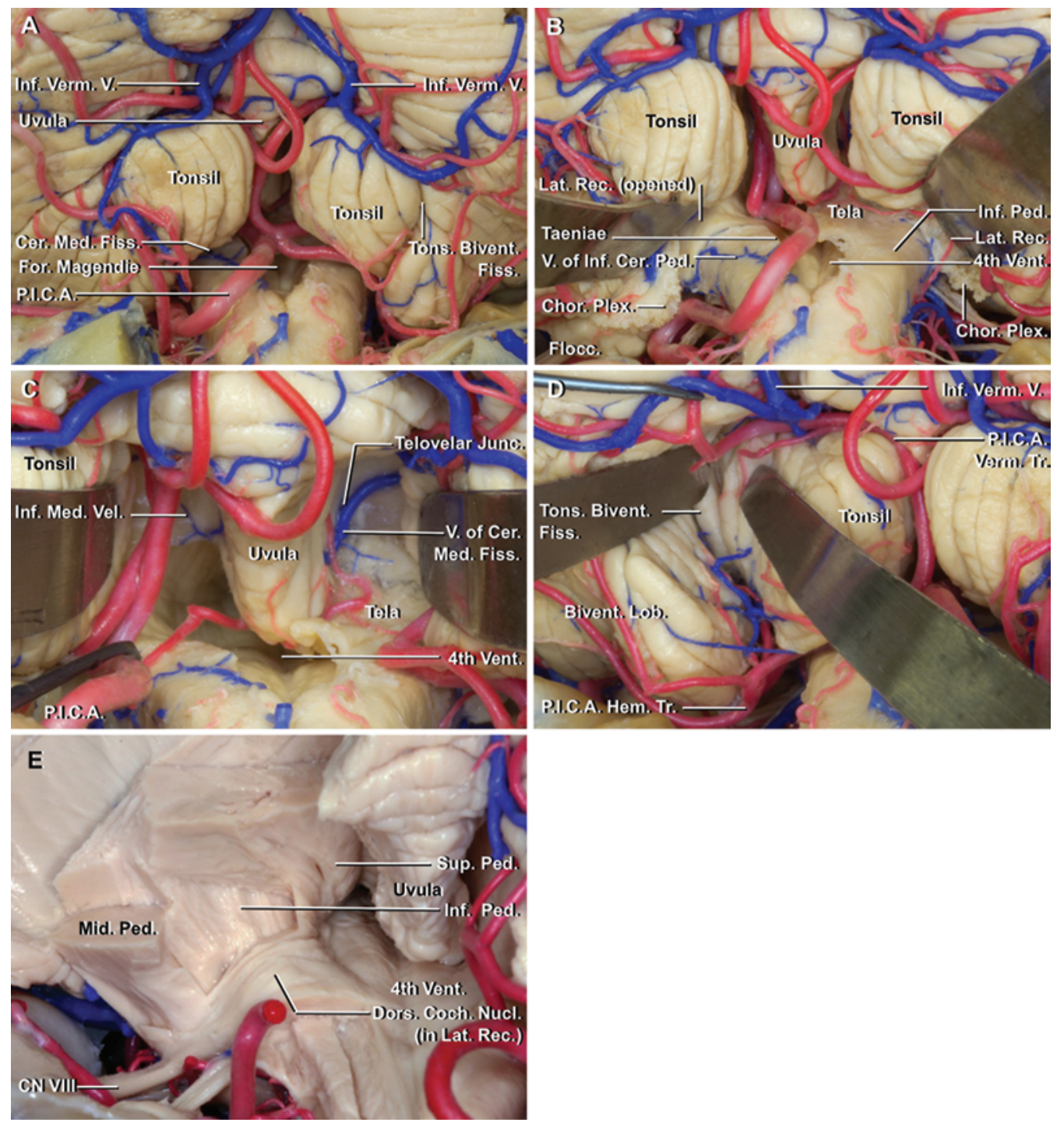

FIG. 7. Telovelar and supratonsillar approaches. A: Midline exposure of the suboccipital surface and cerebellomedullary fissure. B: Opening the medullotonsillar space. The left half of the fourth ventricle and the lateral recess have been opened. The vein of the inferior cerebellar peduncle courses parallel and a few millimeters lateral to the inferolateral edge of the fourth ventricle. C: The uvulotonsillar spaces have been opened. The vein of the cerebellomedullary fissure courses laterally along or near the telovelar junction. D: The left tonsillobiventral fissure is being opened to expose the tonsillar peduncle at the superolateral edge of the tonsil and provide access to the left middle and inferior cerebellar peduncles. The vermian and hemispheric trunks of the PICA arise along the margin of the tonsil. Tributaries of the inferior vermian vein course along this fissure. E: The inferior cerebellar peduncle ascends along the dorsolateral medulla anterior to the dorsal cochlear nucleus and turns dorsally along the rostral margin of the lateral recess to reach the cerebellum. It extends along the lateral edge of the lower half of the fourth ventricle. The middle cerebellar peduncle has been exposed in a fiber dissection lateral to the inferior cerebellar peduncle. Bivent. $=$ biventral; Cer. $=$ cerebellar, cerebello; Chor. Plex. = choroid plexus; $\mathrm{CN}=$ cranial nerve; Coch. $=$ cochlear; Dors. $=$ dorsal; Fiss. $=$ fissure; Flocc. $=$ flocculus; For. = foramen; Hem. = hemispheric; Inf. = inferior; Junc. = junction; Lat. = lateral; Lob. = lobule; Med. = medullary; Mid. $=$ middle; Nucl. = nucleus; P.I.C.A. = posterior inferior cerebellar artery; Ped. = peduncle; Rec. $=$ recess; Sup. $=$ superior; Tons. = tonsillo; Tr. = trunk; V. = vein; Vel. = velum; Vent. = ventricle; Verm. = vermian.

in the fourth ventricle have been proposed as safe entry zones into the brainstem. ${ }^{9,12,13,24,65,79}$ After Stein ${ }^{76,77}$ popularized the median supracerebellar infratentorial approach for pineal region tumors, Voigt and Yaşargil ${ }^{83}$ developed the paramedian variant of this approach. Matsushima et al..$^{50}$ described a more lateral infratentorial route along the anterolateral margin of the tentorial cerebellar surface to CN V in 1989, and Van den Bergh ${ }^{81}$ presented the lateral- paramedian infratentorial approach to pineal tumors in 1990. Recently, Vishteh et al. ${ }^{82}$ extended the latter variant to approach the posterolateral midbrain and ambient cistern, and named it the extreme lateral approach. Vougioukas et al.$^{84}$ published a series of upper brainstem gliomas accessed through an approach called the far-lateral supracerebellar infratentorial approach. The latter 4 approaches (lateral infratentorial, lateral paramedian, extreme lateral, 
and far-lateral) are basically the same, and are called the extreme lateral approach in this study. The supracerebellar infratentorial approach has been divided into 3 variants (median or midline, paramedian, and extreme or far-lateral) based on prior reports. , $17,82^{\text {These variants have been }}$ used to access the pineal region, posterior third ventricle, and posterior and posterolateral aspect of the midbrain and upper pons including the supra- and infracollicular areas and lateral mesencephalic sulcus. ${ }^{3,5,9,17,26,62,71,82}$ The lateral mesencephalic vein is a good landmark for identifying the lateral mesencephalic sulcus. It is difficult to expose the deepest most caudal part of the cerebellomesencephalic fissure, but opening the superior portion of the fissure may help to expand the surgical field. Resection of the upper vermis has been reported to achieve wider exposure of the lower part of the cerebellomesencephalic fissure and superior medullary velum. ${ }^{42}$

The occipital transtentorial approach, which was popularized by Poppen and Jamieson, is an alternative approach to the pineal region, posterior third ventricle, and posterior aspect of the upper brainstem, especially for lesions located in the midline or extending superiorly, or for patients with a steep tentorial slope. ${ }^{26,32,35,58,62,63,87}$ This more superior approach provides greater access to the ipsilateral half of the cerebellomesencephalic fissure, and the supra- and infracollicular areas. ${ }^{59,69}$ Dividing the superior medullary velum after opening the cerebellomesencephalic fissure has been reported as the superior transvelar approach. ${ }^{20}$ This approach provides access to the upper fourth ventricle and the median sulcus above the facial colliculus, yet issues such as the depth and risks of this exposure limit its use. Ezer et al. ${ }^{20}$ have reported that this superior transvelar route along the parietal interhemispheric approach provided access to the entire length of the fourth ventricle floor in the case of an upper pontine cavernous malformation.

\section{Cerebellopontine Fissure}

Reports of approaches through the lateral pons including the middle cerebellar peduncle or peritrigeminal area have recently increased. $3,5,7-9,12,14,21,24,28,29,31,34,39,44,61,64,65,72,78,88$ Fujimaki et al. ${ }^{22}$ reported the opening of the superior limb of the cerebellopontine fissure for the surgical treatment of trigeminal neuralgia, and Ohue et al. ${ }^{61}$ applied it to the lateral pons, calling it the retrosigmoid suprafloccular transhorizontal fissure approach. The suprafloccular approach provides wide exposure of the root entry zones of $\mathrm{CN} \mathrm{V}$ and the middle cerebellar peduncle. This route is also useful for upper cerebellopontine angle tumors, such as petrous apex meningiomas, and the apex of the cerebellopontine fissure has been reported as a preferable place to release CSF and identify the vein of the cerebellopontine fissure, the largest tributary of the superior petrosal vein. ${ }^{47,52}$

The infrafloccular approach was originally proposed for surgical treatments of hemifacial spasm. ${ }^{30}$ The key step to this approach is elevating the flocculus, rhomboid rip, and choroid plexus after opening the inferior part of the inferior limb of the cerebellopontine fissure and superolateral edge of the cerebellomedullary fissure. This route can also be used to access the area around the lateral part of the pontomedullary sulcus or lateral surface of the inferior cerebellar peduncle, which has been recently reported as

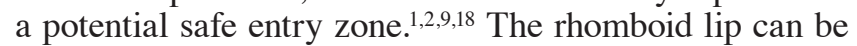
elevated with the flocculus or incised to enter the foramen of Luschka. Opening the lateral edge of the cerebellomedullary fissure also facilitates the superomedial elevation of the biventral lobule, and exposes the dorsolateral medulla and posterior intermediate or lateral sulci, which have been reported as safe medullary entry zones. ${ }^{12,13,24}$ Removing the lateral rim of the foramen magnum, such as in the supracondylar, transcondylar, or transcondylar fossa approaches, may provide a wider operative field, especially when viewed from a caudal direction or dealing with the dorsal medulla. . $^{10,46,54,55,85}$

\section{Cerebellomedullary Fissure}

Multiple proposed safe entry zones to the brainstem located along the floor of the fourth ventricle and dorsal medulla include the supra- and infrafacial triangles, posterior median fissure, posterior intermediate and lateral sulci, and the median sulcus above the facial colliculus., ${ }^{9,12,13,24,40}$ Opening the arachnoid covering the cerebellomedullary fissure provides access to the interior of the fissure and opening the tela and velum in the fissure provides access to the floor and walls of the fourth ventricle. ${ }^{33,35,36,48,49,51,60,80,89}$ These approaches proved an alternative to the transvermian approach, which is the classical approach to the fourth ventricle, which involves splitting the inferior vermis. Arachnoidal dissection of the cerebellomedullary fissure exposes the tonsillomedullary and telovelotonsillar segments of the PICA, the upper dorsal medulla including the inferior cerebellar peduncle, upper posterior median fissure, and posterior intermediate and lateral sulci. Opening the tela choroidea and inferior medullary velum exposes the entire fourth ventricle, including its floor and lateral wall, the supra- and infrafacial triangles, and the median sulcus above the facial colliculus. The caudal surface of the segment of the middle cerebellar peduncle that turns dorsally along the rostral margin of the lateral recess can be accessed through the lateral recess. Opening the cerebellomedullary fissure has also been used to extend the exposure for vertebral artery-PICA aneurysms and glossopharyngeal neuralgia and other lesions in the lower cerebellopontine angle adjacent to the cerebellomedullary cistern. ${ }^{53}$ Opening the tonsillobiventral fissure and retracting the tonsil inferomedially has recently been reported as the supratonsillar approach to the dentate nucleus and middle and inferior cerebellar peduncles. ${ }^{41}$

\section{Conclusions}

The anatomy of the cerebellar-brainstem and cerebellar fissures, and the various approaches involving the opening of these fissures, has been examined. Opening these fissures provides wide exposure of the brainstem surfaces, segments of the cerebellar arteries and veins, and vital neural structures hidden by the cerebellum.

\section{Acknowledgments}

We would like to express our gratitude to Robin Barry, MA, for her assistance in preparing and completing the figures, and to Jessica Striley, BS, and Kae Watanabe, MD, for their assistance in 
preparing and completing this manuscript. Financial support for this study was received from the University of Florida Foundation.

\section{References}

1. Abla AA, Benet A, Lawton MT: The far lateral transpontomedullary sulcus approach to pontine cavernous malformations: technical report and surgical results. Neurosurgery $\mathbf{1 0}$ (Suppl 3):472-480, 2014

2. Abla AA, Clark AJ, Lawton ML: Resection of pontine cavernous malformation through the pontomedullary sulcus. Neurosurg Focus 36 (1 Suppl): 1, 2014

3. Abla AA, Lekovic GP, Turner JD, de Oliveira JG, Porter R, Spetzler RF: Advances in the treatment and outcome of brainstem cavernous malformation surgery: a single-center case series of 300 surgically treated patients. Neurosurgery 68:403-415, 2011

4. Abla AA, Spetzler RF: Brainstem cavernoma surgery: the state of the art. World Neurosurg 80:44-46, 2013

5. Abla AA, Turner JD, Mitha AP, Lekovic G, Spetzler RF: Surgical approaches to brainstem cavernous malformations. Neurosurg Focus 29(3):E8, 2010

6. Ammirati M, Bernardo A, Musumeci A, Bricolo A: Comparison of different infratentorial-supracerebellar approaches to the posterior and middle incisural space: a cadaveric study. J Neurosurg 97:922-928, 2002

7. Asaad WF, Walcott BP, Nahed BV, Ogilvy CS: Operative management of brainstem cavernous malformations. Neurosurg Focus 29(3):E10, 2010

8. Baghai P, Vries JK, Bechtel PC: Retromastoid approach for biopsy of brain stem tumors. Neurosurgery 10:574-579, 1982

9. Bertalanffy H, Benes L, Miyazawa T, Alberti O, Siegel AM, Sure U: Cerebral cavernomas in the adult. Review of the literature and analysis of 72 surgically treated patients. Neurosurg Rev 25:1-55, 2002

10. Bertalanffy H, Seeger W: The dorsolateral, suboccipital, transcondylar approach to the lower clivus and anterior portion of the craniocervical junction. Neurosurgery 29:815821,1991

11. Bertalanffy H, Tissira N, Krayenbühl N, Bozinov O, Sarnthein J: Inter- and intrapatient variability of facial nerve response areas in the floor of the fourth ventricle. Neurosurgery 68 (1 Suppl Operative):23-31, 2011

12. Bricolo A: Surgical management of intrinsic brain stem gliomas. Op Tech Neurosurg 3:137-154, 2000

13. Bricolo A, Turazzi S: Surgery for gliomas and other mass lesions of the brainstem. Adv Tech Stand Neurosurg 22:261341, 1995

14. Cantore G, Missori P, Santoro A: Cavernous angiomas of the brain stem. Intra-axial anatomical pitfalls and surgical strategies. Surg Neurol 52:84-94, 1999

15. Chen LH, Zhang HT, Chen L, Liu LX, Xu RX: Minimally invasive resection of brainstem cavernous malformations: surgical approaches and clinical experiences with 38 patients. Clin Neurol Neurosurg 116:72-79, 2014

16. Dammers R, Delwel EJ, Krisht AF: Cavernous hemangioma of the mesencephalon: tonsillouveal transaqueductal approach. Neurosurgery 64 (5 Suppl 2):296-300, 2009

17. de Oliveira JG, Lekovic GP, Safavi-Abbasi S, Reis CV, Hanel RA, Porter RW, et al: Supracerebellar infratentorial approach to cavernous malformations of the brainstem: surgical variants and clinical experience with 45 patients. Neurosurgery 66:389-399, 2010

18. Deshmukh VR, Rangel-Castilla L, Spetzler RF: Lateral inferior cerebellar peduncle approach to dorsolateral medullary cavernous malformation. J Neurosurg 121:723-729, 2014

19. Dukatz T, Sarnthein J, Sitter H, Bozinov O, Benes L, Sure U, et al: Quality of life after brainstem cavernoma surgery in 71 patients. Neurosurgery 69:689-695, 2011
20. Ezer H, Banerjee AD, Bollam P, Guthikonda B, Nanda A: The superior transvelar approach to the fourth ventricle and brainstem. J Neurol Surg B Skull Base 73:175-182, 2012

21. Ferroli P, Sinisi M, Franzini A, Giombini S, Solero CL, Broggi G: Brainstem cavernomas: long-term results of microsurgical resection in 52 patients. Neurosurgery 56:12031214,2005

22. Fujimaki T, Kirino T: Combined transhorizontal-supracerebellar approach for microvascular decompression of trigeminal neuralgia. Br J Neurosurg 14:531-534, 2000

23. Garrett M, Spetzler RF: Surgical treatment of brainstem cavernous malformations. Surg Neurol 72 Suppl 2:S3-S10, 2009

24. Giliberto G, Lanzino DJ, Diehn FE, Factor D, Flemming KD, Lanzino G: Brainstem cavernous malformations: anatomical, clinical, and surgical considerations. Neurosurg Focus 29(3):E9, 2010

25. Gross BA, Batjer HH, Awad IA, Bendok BR: Brainstem cavernous malformations. Neurosurgery 64:E805-E818, 2009

26. Gross BA, Batjer HH, Awad IA, Bendok BR, Du R: Brainstem cavernous malformations: 1390 surgical cases from the literature. World Neurosurg 80:89-93, 2013

27. Hardy DG, Peace DA, Rhoton AL Jr: Microsurgical anatomy of the superior cerebellar artery. Neurosurgery 6:10-28, 1980

28. Hauck EF, Barnett SL, White JA, Samson D: The presigmoid approach to anterolateral pontine cavernomas. Clinical article. J Neurosurg 113:701-708, 2010

29. Hebb MO, Spetzler RF: Lateral transpeduncular approach to intrinsic lesions of the rostral pons. Neurosurgery 66 (3 Suppl Operative):26-29, 2010

30. Hitotsumatsu T, Matsushima T, Inoue T: Microvascular decompression for treatment of trigeminal neuralgia, hemifacial spasm, and glossopharyngeal neuralgia: three surgical approach variations: technical note. Neurosurgery 53:14361443,2003

31. Hu P, Liang J, Bao Y, Li M, Ling F: The pterional transsylvian transtentorial approach to ventrolateral pontine cavernomas: indications and techniques. World Neurosurg 82:1276-1282, 2014

32. Jamieson KG: Excision of pineal tumors. J Neurosurg 35:550-553, 1971

33. Jean WC, Abdel Aziz KM, Keller JT, van Loveren HR: Subtonsillar approach to the foramen of Luschka: an anatomic and clinical study. Neurosurgery 52:860-866, 2003

34. Kashimura H, Inoue T, Ogasawara K, Ogawa A: Pontine cavernous angioma resected using the subtemporal, anterior transpetrosal approach determined using three-dimensional anisotropy contrast imaging: technical case report. Neurosurgery 58:ONS-E1751, ONS-E175, 2006

35. Kawashima M, Matsushima T, Nakahara Y, Takase Y, Masuoka J, Ohata K: Trans-cerebellomedullary fissure approach with special reference to lateral route. Neurosurg Rev 32:457-464, 2009

36. Kellogg JX, Piatt JH Jr: Resection of fourth ventricle tumors without splitting the vermis: the cerebellomedullary fissure approach. Pediatr Neurosurg 27:28-33, 1997

37. Kikuta K, Nozaki K, Takahashi JA, Miyamoto S, Kikuchi $\mathrm{H}$, Hashimoto N: Postoperative evaluation of microsurgical resection for cavernous malformations of the brainstem. J Neurosurg 101:607-612, 2004

38. Kin T, Nakatomi H, Shojima M, Tanaka M, Ino K, Mori H, et al: A new strategic neurosurgical planning tool for brainstem cavernous malformations using interactive computer graphics with multimodal fusion images. J Neurosurg 117:78-88, 2012

39. Konovalov AN, Spallone A, Makhmudov UB, Kukhlajeva JA, Ozerova VI: Surgical management of hematomas of the brain stem. J Neurosurg 73:181-186, 1990 
40. Kyoshima K, Kobayashi S, Gibo H, Kuroyanagi T: A study of safe entry zones via the floor of the fourth ventricle for brain-stem lesions. Report of three cases. J Neurosurg 78:987-993, 1993

41. Lawton MT, Quinones-Hinojosa A, Jun P: The supratonsillar approach to the inferior cerebellar peduncle: anatomy, surgical technique, and clinical application to cavernous malformations. Neurosurgery 59 (4 Suppl 2):ONS244-251, ONS251-252, 2006

42. Lekovic GP, Porter RW, Spetzler RF: Supratentorial and infratentorial cavernous malformations, in Winn HR, Youmans JR (eds): Youmans Neurological Surgery, ed 6. Philadelphia: WB Saunders, 2011, pp 4134-4152

43. Lister JR, Rhoton AL Jr, Matsushima T, Peace DA: Microsurgical anatomy of the posterior inferior cerebellar artery. Neurosurgery 10:170-199, 1982

44. Mai JC, Ramanathan D, Kim LJ, Sekhar LN: Surgical resection of cavernous malformations of the brainstem: evolution of a minimally invasive technique. World Neurosurg 79:691-703, 2013

45. Martin RG, Grant JL, Peace D, Theiss C, Rhoton AL Jr: Microsurgical relationships of the anterior inferior cerebellar artery and the facial-vestibulocochlear nerve complex. Neurosurgery 6:483-507, 1980

46. Matsushima K, Kawashima M, Matsushima T, Hiraishi T, Noguchi T, Kuraoka A: Posterior condylar canals and posterior condylar emissary veins-a microsurgical and CT anatomical study. Neurosurg Rev 37:115-126, 2014

47. Matsushima K, Matsushima T, Kuga Y, Kodama Y, Inoue $\mathrm{K}$, Ohnishi H, et al: Classification of the superior petrosal veins and sinus based on drainage pattern. Neurosurgery 10 (Suppl 2):357-367, 2014

48. Matsushima T, Abe H, Kawashima M, Inoue T: Exposure of the wide interior of the fourth ventricle without splitting the vermis: importance of cutting procedures for the tela choroidea. Neurosurg Rev 35:563-572, 2012

49. Matsushima T, Fukui M, Inoue T, Natori Y, Baba T, Fujii K: Microsurgical and magnetic resonance imaging anatomy of the cerebello-medullary fissure and its application during fourth ventricle surgery. Neurosurgery 30:325-330, 1992

50. Matsushima T, Fukui M, Suzuki S, Rhoton AL Jr: The microsurgical anatomy of the infratentorial lateral supracerebellar approach to the trigeminal nerve for tic douloureux. Neurosurgery 24:890-895, 1989

51. Matsushima T, Inoue T, Inamura T, Natori Y, Ikezaki K, Fukui M: Transcerebellomedullary fissure approach with special reference to methods of dissecting the fissure. J Neurosurg 94:257-264, 2001

52. Matsushima T, Kawashima M, Inoue K, Matsushima K: Anatomy of the superior petrosal veins and their exposure and management during petrous apex meningioma surgery using the lateral suboccipital retrosigmoid approach. Neurosurg Rev 37:535-456, 2014

53. Matsushima T, Kawashima M, Inoue K, Matsushima K, Miki $\mathrm{K}$ : Exposure of wide cerebellomedullary cisterns for vascular lesion surgeries in cerebellomedullary cisterns: opening of unilateral cerebellomedullary fissure combined with lateral foramen magnum approach. World Neurosurg 82:e615e621, 2014

54. Matsushima T, Matsukado K, Natori Y, Inamura T, Hitotsumatsu T, Fukui M: Surgery on a saccular vertebral arteryposterior inferior cerebellar artery aneurysm via the transcondylar fossa (supracondylar transjugular tubercle) approach or the transcondylar approach: surgical results and indications for using two different lateral skull base approaches. J Neurosurg 95:268-274, 2001

55. Matsushima T, Natori Y, Katsuta T, Ikezaki K, Fukui M, Rhoton AL: Microsurgical anatomy for lateral approaches to the foramen magnum with special reference to transcondylar fossa (supracondylar transjugular tubercle) approach. Skull Base Surg 8:119-125, 1998

56. Matsushima T, Rhoton AL Jr, de Oliveira E, Peace D: Microsurgical anatomy of the veins of the posterior fossa. J Neurosurg 59:63-105, 1983

57. Matsushima T, Rhoton AL Jr, Lenkey C: Microsurgery of the fourth ventricle: Part 1. Microsurgical anatomy. Neurosurgery 11:631-667, 1982

58. McLaughlin N, Martin NA: The occipital interhemispheric transtentorial approach for superior vermian, superomedian cerebellar, and tectal arteriovenous malformations: advantages, limitations, and alternatives. World Neurosurg 82:409-416, 2014

59. Moshel YA, Parker EC, Kelly PJ: Occipital transtentorial approach to the precentral cerebellar fissure and posterior incisural space. Neurosurgery 65:554-564, 2009

60. Mussi AC, Rhoton AL Jr: Telovelar approach to the fourth ventricle: microsurgical anatomy. J Neurosurg 92:812-823, 2000

61. Ohue S, Fukushima T, Friedman AH, Kumon Y, Ohnishi T: Retrosigmoid suprafloccular transhorizontal fissure approach for resection of brainstem cavernous malformation. Neurosurgery 66 (6 Suppl Operative):306-313, 2010

62. Ohue S, Fukushima T, Kumon Y, Ohnishi T, Friedman AH: Surgical management of brainstem cavernomas: selection of approaches and microsurgical techniques. Neurosurg Rev 33:315-324, 2010

63. Poppen JL: The right occipital approach to a pinealoma. J Neurosurg 25:706-710, 1966

64. Porter RW, Detwiler PW, Spetzler RF, Lawton MT, Baskin JJ, Derksen PT, et al: Cavernous malformations of the brainstem: experience with 100 patients. J Neurosurg 90:50-58, 1999

65. Recalde RJ, Figueiredo EG, de Oliveira E: Microsurgical anatomy of the safe entry zones on the anterolateral brainstem related to surgical approaches to cavernous malformations. Neurosurgery 62 (3 Suppl 1):9-17, 2008

66. Rhoton AL Jr: The cerebellar arteries. Neurosurgery 47 (3 Suppl):S29-S68, 2000

67. Rhoton AL Jr: Cerebellum and fourth ventricle. Neurosurgery 47 (3 Suppl):S7-S27, 2000

68. Rhoton AL Jr: The posterior fossa veins. Neurosurgery 47 (3 Suppl):S69-S92, 2000

69. Rhoton AL Jr: Tentorial incisura. Neurosurgery 47 (3 Suppl):S131-S153, 2000

70. Samii M, Eghbal R, Carvalho GA, Matthies C: Surgical management of brainstem cavernomas. J Neurosurg 95:825-832, 2001

71. Sanai N, Mirzadeh Z, Lawton MT: Supracerebellar-supratrochlear and infratentorial-infratrochlear approaches: gravity-dependent variations of the lateral approach over the cerebellum. Neurosurgery 66 (6 Suppl Operative):264-274, 2010

72. Sandalcioglu IE, Wiedemayer H, Secer S, Asgari S, Stolke D: Surgical removal of brain stem cavernous malformations: surgical indications, technical considerations, and results. J Neurol Neurosurg Psychiatry 72:351-355, 2002

73. Sarnthein J, Bozinov O, Melone AG, Bertalanffy H: Motorevoked potentials (MEP) during brainstem surgery to preserve corticospinal function. Acta Neurochir (Wien) 153:1753-1759, 2011

74. Shimizu S, Tanaka R, Rhoton AL Jr, Fukushima Y, Osawa S, Kawashima M, et al: Anatomic dissection and classic threedimensional documentation: a unit of education for neurosurgical anatomy revisited. Neurosurgery 58:E1000, 2006

75. Sindou M, Yada J, Salord F: Functional results after microsurgical resection of brain stem cavernous malformations (retrospective study of a 12 patient series and review of the recent literature). Acta Neurochir (Wien) 142:843-853, 2000 
76. Stein BM: The infratentorial supracerebellar approach to pineal lesions. J Neurosurg 35:197-202, 1971

77. Stein BM: Supracerebellar-infratentorial approach to pineal tumors. Surg Neurol 11:331-337, 1979

78. Steňo J, Bízik I, Steňová J, Timárová G: Subtemporal transtentorial resection of cavernous malformations involving the pyramidal tract in the upper pons and mesencephalon. Acta Neurochir (Wien) 153:1955-1962, 2011

79. Strauss C, Lütjen-Drecoll E, Fahlbusch R: Pericollicular surgical approaches to the rhomboid fossa. Part I. Anatomical basis. J Neurosurg 87:893-899, 1997

80. Tanriover N, Ulm AJ, Rhoton AL Jr, Yasuda A: Comparison of the transvermian and telovelar approaches to the fourth ventricle. J Neurosurg 101:484-498, 2004

81. Van den Bergh R: Lateral-paramedian infratentorial approach in lateral decubitus for pineal tumours. Clin Neurol Neurosurg 92:311-316, 1990

82. Vishteh AG, David CA, Marciano FF, Coscarella E, Spetzler RF: Extreme lateral supracerebellar infratentorial approach to the posterolateral mesencephalon: technique and clinical experience. Neurosurgery 46:384-389, 2000

83. Voigt K, Yaşargil MG: Cerebral cavernous haemangiomas or cavernomas. Incidence, pathology, localization, diagnosis, clinical features and treatment. Review of the literature and report of an unusual case. Neurochirurgia (Stuttg) 19:5968,1976

84. Vougioukas VI, Omran H, Gläsker S, Van Velthoven V: Far lateral supracerebellar infratentorial approach for the treatment of upper brainstem gliomas: clinical experience with pediatric patients. Childs Nerv Syst 21:1037-1041, 2005

85. Wen HT, Rhoton AL Jr, Katsuta T, de Oliveira E: Microsurgical anatomy of the transcondylar, supracondylar, and paracondylar extensions of the far-lateral approach. J Neurosurg 87:555-585, 1997

86. Yagmurlu K, Rhoton AL Jr, Tanriover N, Bennett JA: Three- dimensional microsurgical anatomy and the safe entry zones of the brainstem. Neurosurgery 10 (Suppl 4):602-620, 2014

87. Yamamoto I: Pineal region tumor: surgical anatomy and approach. J Neurooncol 54:263-275, 2001

88. Zausinger S, Yousry I, Brueckmann H, Schmid-Elsaesser $\mathrm{R}$, Tonn JC: Cavernous malformations of the brainstem: three-dimensional-constructive interference in steady-state magnetic resonance imaging for improvement of surgical approach and clinical results. Neurosurgery 58:322-330, 2006

89. Ziyal IM, Sekhar LN, Salas E: Subtonsillar-transcerebellomedullary approach to lesions involving the fourth ventricle, the cerebellomedullary fissure and the lateral brainstem. Br J Neurosurg 13:276-284, 1999

\section{Disclosure}

The authors report no conflict of interest concerning the materials or methods used in this study or the findings specified in this paper.

\section{Author Contributions}

Conception and design: Rhoton, Matsushima. Acquisition of data: Matsushima, Yagmurlu. Analysis and interpretation of data: Rhoton, Matsushima, Yagmurlu. Drafting the article: Matsushima, Yagmurlu. Critically revising the article: all authors. Reviewed submitted version of manuscript: all authors. Approved the final version of the manuscript on behalf of all authors: Rhoton. Administrative/technical/material support: Rhoton. Study supervision: Rhoton.

\section{Correspondence}

Albert L. Rhoton, Jr., University of Florida, Department of Neurosurgery, P.O. Box 100265, Gainesville, FL 32610-0265. email: rhoton@neurosurgery.ufl.edu. 